\title{
Mia Couto: o outro lado das palavras e dos sonhos
}

\author{
Carmen Lucia Tindó Ribeiro Secco ${ }^{1}$ \\ Universidade Federal do Rio de Janeiro
}

RESUMO: O PRESENTE TRABALHO MOSTRA A VISÃO MÍTICA E POÉTICA DA EXISTÊNCIA NA OBRA DE MIA COUTO, CONSTRUÍDA POR MEIO DE UM OLHAR CRÍTICO ACERCA DA HISTÓRIA DA SUA NAÇÃO, APÓS TANTOS ANOS DE GUERRA E DE VIOLÊNCIA. COM BASE NOS ELEMENTOS AR, ÁGUA, SONHO E IMAGINAÇÃO POÉTICA, O AUTOR FAZ, DA LITERATURA, UM MEIO DE CONSCIÊNCIA POĹTICA E CULTURAL.

\begin{abstract}
THIS PAPER SHOWS THE MYTHICAL AND POETIC VISION IN MIA COUTO'S WRITINGS, BUILT THROUGH A CRITICAL LOOK TO MOZAMBIQUE'S HISTORY AFTER SO MANY YEARS OF WAR AND VIOLENCE. BASED ON THE ELEMENTS AIR, WATER, DREAM AND POETIC IMAGINATION, COUTO TRANSFORMS HIS LITERATURE INTO A MEANS OF POLITICAL AND CULTURAL ENLIGHTENMENT.
\end{abstract}

PALAVRAS-CHAVE: MIA COUTO - LITERATURA MOÇAMBICANA - SONHO - IMAGINAĊÃO POÉTICA - CONSCIÊNCIA CULTURAL

KEY-WORDS: MIA COUTO - MOZAMBICAN LITERATURE - DREAM - POETIC IMAGINATION - CULTURAL CONSCIOUSNESS

\footnotetext{
${ }^{1}$ Carmen Lucia Tindó Ribeiro Secco é doutora em Letras Vernáculas (UFRJ, 1992), supervisora do setor de Literaturas Africanas de Língua Portuguesa da Faculdade de Letras da Universidade Federal do Rio de Janeiro e pesquisadora do CNPq.
} 
itos, ritos e sonhos são caminhos ficcionais trilhados pelas narrativas de Mia Couto que enveredam pelos labirintos e ruínas da memória coletiva moçambicana como uma forma encontrada para resistir à morte das tradições causada pelas destruições advindas da guerra. As úlceras deixadas nas paisagens são deploradas pela escritura mitopoética do autor, cujo lirismo funciona como bálsamo cicatrizante e cuja lucidez política serve para abrir os olhos do povo, numa tentativa de curar a cegueira reinante em Moçambique, nos tempos pós-Independência.

Grande parte das narrativas de Mia Couto utiliza o insólito como meio de criticar o real opressor e de subverter os cânones da racionalidade européia. Seus textos fundam uma semiose libertadora, cuja ação, por intermédio de representações oníricas, faz aflorar o imaginário cultural popular, que foi censurado tanto no período colonial, como nos primeiros anos após a libertação, quando a orientação marxista ortodoxa do Governo da Revolução proibia, de modo geral, as manifestações religiosas.

O discurso literário de Mia Couto tece uma rede intertextual e simbólica com os mitos e as crenças dos povos moçambicanos. Trabalha metaforicamente a linguagem e recria a língua portuguesa com os saberes e ritmos locais, efetuando construções morfossintáticas e semânticas inusitadas, que visam à recuperação de sentidos poéticos da vida, escamoteados pelos anos de longo sofrimento vivido por Moçambique.

Alguns dos processos de revitalização da linguagem empregados pelo escritor moçambicano se assemelham aos usados por Guimarães Rosa. Os mais freqüentes são os neologismos formados por afixação e aglutinação. Do primeiro tipo, citamos vários exemplos: imovente, irresultava, sofrências, amanhãzinha, entre outros; do segundo, lembramos a palavra cabisbaixeza, resultado da fusão dos vocábulos cabisbaixo e tristę̧a. São comuns também os neologismos de função, nos quais há a mudança da classe usual da palavra, conforme ocorre em titiar e lagrimava, verbos, respectivamente, derivados dos substantivos "titia" e "lágrima".

A constante artesania verbal, a recriação de vocábulos e frases, o uso de neologismos, o humor pela subversão de sentidos habituais, o emprego de uma sintaxe especial, a técnica do "desenredo" aproximam o discurso do escritor moçambicano do de Guimarães Rosa, Luandino Vieira e Manuel de Barros. Num estilo semelhante ao desses autores, Mia Couto faz de sua es- 
critura uma poiesis inovadora, que consegue reescrever seu país de uma forma original, na medida em que sua escrita se apresenta revitalizada pelos jogos poéticos com a linguagem e pela incorporação de traços da oratura recolhidos de algumas comunidades do interior de Moçambique.

Explorando as possibilidades latentes no português, o autor reinventa esse idioma, levando-o, pela morfologia e sintaxe contaminadas por construções modificadas pelos falares moçambicanos, a expressar as marcas multiculturais presentes no imaginário lingüístico do país. A pontuação empregada é mais estética que gramatical, acompanhando o ritmo e a entonação da fala e dos sentimentos das personagens. Embora não despreze totalmente as regras da gramática oficial, o estilo do escritor não hesita em transgredir a norma culta do português trazido pela colonização, para alcançar efeitos poéticos originais.

Como a ficção de Guimarães Rosa, constatamos que a de Mia Couto também apreende mitopoeticamente o real, ensinando outras sensibilidades e novas maneiras de pensar não só a nação, mas também a dimensão existencial dos seres humanos.

Concebendo a poesia em seu significado amplo, ou seja, como substância imaterial capaz de provocar respostas estéticas em outros seres humanos, consideramos poéticos os textos, tanto em verso, como em prosa, cuja densidade conotativa e a condensação da linguagem motivam a descida "ao fundo do desconhecido para encontrar o novo” (BAUDELAIRE apud LYRA, 1986: 6).

É comum ouvir que a poesia está no mundo, entretanto, ela só se realiza pela transitividade simbólica do discurso, ou seja, pela sensibilidade criadora que apenas se consuma quando atinge a emoção da leitura.

O poeta é um “doador de sentidos" (BOSI, 1983: 141), é aquele cuja linguagem não se faz apenas de ritmos e palavras, mas prima também pelo compromisso político de pensar o homem e a sociedade. A escritura poética é, pois, o produto de uma semiose que funde, literariamente, lirismo e lucidez na captação do mundo e da existência.

"O ser e o tempo da poesia", segundo Alfredo Bosi, são diversos. Através dos séculos, o poético vai adquirindo novas feições, e, na modernidade, se caracteriza, principalmente, pela recusa do consumo e da violência, enveredando por vias diferentes de resistência: a paródia, a metalinguagem, a rebeldia, as utopias políticas, a mitologia, a memória, entre outras. 
Escolhemos trabalhar um texto de Mia Couto, escritor moçambicano contemporâneo, pois sua obra apresenta um grande vigor poético, uma textualidade rica em lirismo e dotada de profunda consciência social. O autor, embora tenha só um livro de poesia e uma dedicação maior à ficção, nunca deixou de trabalhar a poesia em sua linguagem. Suas narrativas, apesar da preocupação evidente em apreender a oralidade e as tradições de diversas etnias moçambicanas, constituem-se como prosa poética, na medida em que a ludicidade do fazer literário se impõe como desafio permanente.

Em entrevista concedida ao escritor angolano José Eduardo Agualusa, Mia Couto declara que seu "fascínio pelas histórias resulta da necessidade absoluta de brincar. [...] Como um gato perante o novelo, assim estamos ante o texto que nos encanta" (COUTO, 1997: 59).

Elegemos para análise, dentre outros, o conto "Cataratas do céu", do livro Contos do nascer da terra, publicado em 1997, pois esse texto evidencia como o real e o "supra-real" se interpenetram na ficção de Mia Couto, exorcizando, poeticamente, os fantasmas da história moçambicana.

O enredo do conto é simples e linear. A beleza da narrativa se impõe pelo lirismo e pela poesia da linguagem, cuja emotividade atinge as profundezas da alma humana. A narrativa versa sobre a inadaptação de um miúdo do interior de Moçambique, que, órfão de pai e mãe, fora morar com os tios na cidade.

"Desterritorializado", conforme expressão de Guattari, o garoto se assusta com os ruídos urbanos, sentindo-se um estrangeiro naquele espaço. Medo e insegurança o fecham em si mesmo, com os olhos sempre postos no chão. Os tios, preocupados, tentam tirá-lo daquela tristeza. Entretanto, seus esforços são em vão. A voz narradora em terceira pessoa é que efetua o contraponto poético, expressando reflexões de ordem social, filosófica e existencial: "O menino era desses que a guerra deslocou não só de endereço mas da vida" (COUTO, 1997: 229).

Inconformado com o alheamento do sobrinho, o tio busca, a princípio, explicações nas crenças religiosas populares: "Esse mufana foi é mal-olhado!” (COUTO, 1997: 230). Depois, continua a procurar outras razões, até que, numa noite, acorda sobressaltado, dizendo:

Eu sei o que sucede com ele, esse nosso sobrinhito não é um deslocado de guerra. A guerra é que deslocou-se para dentro dele. E agora, como tirar a 
guerra lá dos interiores, como desalojar a malvada lá das províncias da alma? (COUTO, 1997: 230)

A tensão narrativa vai sendo armada pelo confronto entre o absoluto silêncio do menino e a fala angustiada do tio. A mulher, ponderada e com receio de magoar ainda mais o miúdo, tenta dissuadir o esposo, mostrandolhe que o melhor seria ela apenas titiar o sobrinho.

Mesclando os discursos diretos das personagens à poeticidade de sua narração, a voz enunciadora, por meio da técnica do discurso indireto livre, penetra nos pensamentos do casal de tios e reflete sobre a guerra, por intermédio de expressões e provérbios característicos da oratura e do modo moçambicano de pensar:

Deixa-lhe, marido. Era conselho da velha tia. Ela entendia de feridas e sofrências. Quando o pão é magro quem escasseia é o homem. Sabe-se o que aquele menino passara, lá de onde vinha? O marido que se dispensasse. Aquilo era assunto de ternura e mãe. (COUTO, 1997: 230; grifo nosso)

De nada valeu, porém, a sabedoria da velha mulher. O marido permaneceu no propósito de modificar, de qualquer modo, o sobrinho. Ao descobrir o pavor que este sentia quando ouvia um avião sobrevoar a casa, o tio, sem intuir que esse ruído despertava no miúdo a memória da guerra e da morte dos pais, decide que o remédio era levar a criança até o aeroporto: “Amanhãzinha vais ver aviões, adiante do céu, barulharem até te encheres de ouvidos" (COUTO, 1997: 230).

Bem-intencionado, mas sem a sensibilidade necessária, o homem não entendia que sua resolução só fazia aumentarem os temores do garoto. Vaidoso, continuava a expor, com veemência, seus argumentos à esposa: "O que ele precisa é o céu se abrir para ele. Compreende, mulher? A terra está cheia de ferida, não traz consolo nem ombro para ninguém. O céu é que, agora, tem que se abrir para ele" (COUTO, 1997: 230).

O homem pensava que, fazendo o sobrinho olhar para cima, conseguiria tirá-lo daquela cabisbaixeza (COUTO, 1997: 229). Só que a alma humana não é tão simples assim, nem se resolve dicotomicamente...

Ao voltar do aeroporto, mais rígido ainda ficou o miúdo: não deitava, não dormia, e, na manhã seguinte, surpreendeu os tios com o desejo de ser avião. 
Os parentes riram, sem compreenderem, na verdade, o que lhe ia no âmago. O menino emudeceu de vez e se isolou no quarto: "Os braços cumpriam ordem de serem asas, o corpo duro, quase metálico" (COUTO, 1997: 231).

A dramaticidade narrativa cresce, estruturada pela tensão opositiva entre os binômios: ALTO/BAIXO, CÉU/CHÃO, TIO/SOBRINHO, LIBERDADE/ MEDO. Outro par dicotômico é formado, no espaço ficcional, pelo significativo jogo entre CALAR e FALAR, entre o sobrinho imovente e o tio, insistente, a perguntar: “- Não preferes ser um pássaro, vizinho de alegrias?” (COUTO, 1997: 231). Mas, como comenta o narrador, "tudo irresultava" (COUTO, 1997: 231), e, de novo, os dois voltam ao aeroporto. A narrativa chega, assim, ao máximo de tensão e se encaminha para seu clímax.

Vendo o menino, com os braços hirtos, como se fossem de aço, a correr na pista de decolagem, por entre as aeronaves que chegavam e partiam, o tio se lagrimava, comovido: “- Veja, veja como ele brinca!” (COUTO, 1997: 231). Cúmplice da ilusão daquilo que sonhara, nem se apercebia do perigo iminente a pôr em risco a vida do sobrinho...

Nesse momento de maior tragicidade e suspense, o mágico e o "surreal" invadem a ficção. O sonho do tio e o do menino se cruzam simultâneos, mas cada um a seu modo. O do homem, que realiza seu desejo de ver o miúdo em brincadeiras de infância; o do menino, que se converte na fantasia de ser o monstruoso pássaro de metal que levara para muito longe os seus pais.

O texto termina em aberto, de forma insólita, mas intensamente lírica, como comprova o último parágrafo, que a seguir transcrevemos:

E assim ganhando mais e mais velocidade, braços cruzando o sonho, o menino se confundia, a contraluz, com o fogo inteiro do poente. Seria, no instante, que o céu se abria para aquela criaturita?

Pupila esgrimando o sol, o tio deixou de ver o miúdo. Apenas uma mancha, sombra súbita cruzando os ares. Ainda acreditou ser um pássaro que lançava seu vôo da varanda para o distante chão. Nesse momento ele aprendia que o céu está padecendo de cataratas, repentinas névoas que impedem Deus de nos espreitar. (COUTO, 1997: 231-2)

Deixando o leitor em hesitação, como é próprio do gênero "fantástico", o desfecho do conto permite várias leituras. A metáfora do avião se faz 
polissêmica, podendo ser interpretada por diferentes ângulos: o do tio imaginando o sobrinho em alegrias de voar como fazem as crianças; o do menino, metamorfoseado em metálica ave, indo para o céu, em busca dos pais; e, finalmente, o do narrador, cujo vôo da criação, descrevendo poeticamente a morte do menino atropelado pelas aeronaves, denuncia as cataratas do céu, imagem que, alegoricamente, representa a falta de visão da maioria dos moçambicanos, impedidos de enxergar o próprio país, ainda envolto por névoas de lágrimas e dores. Explica-se, assim, a metáfora que dá título ao conto. A voz do narrador se mistura à do poeta. E este, conforme teoriza o filósofo Gaston Bachelard, "unindo o terrestre ao aéreo, subindo e descendo, nas próprias palavras, faz a linguagem sonhar" (BACHELARD, 1989: 43).

Mas as "letras do sonho", em Mia Couto, nunca abandonam a dimensão social e filosófica da história, pois, abrindo os olhos e os corações daqueles que tiveram as emoções e os sentidos enevoados pela guerra, se convertem em exercício de reflexão crítica contra qualquer forma de opressão, arbítrio ou crueldade. Porém, essa reflexão é feita pelo autor com a fineza e a ternura dos profundos sentimentos, como ele próprio adverte no prefácio do livro:

Não é da luz do sol que carecemos. Milenarmente a grande estrela iluminou a terra e, afinal, nós pouco aprendemos a ver. O mundo necessita ser visto sob outra luz: a luz do luar, essa claridade que cai com respeito e delicadeza. Só o luar revela o lado feminino dos seres. Só a lua revela a intimidade de nossa morada terrestre. (COUTO, 1997: 7)

Se o tio do conto "Cataratas do céu" houvesse permitido à mulher as femininas afeições, talvez o sobrinho, embalado pelos carinhos lunares da velha tia, não tivesse sido tragado pelo sol, cuja potente luz, como vimos no texto, também é capaz de cegar.

$\mathrm{Na}$ ficção de Mia Couto, o ar e os sonhos são imagens recorrentes e, geralmente, metaforizam a imaginação poética, confirmando, assim, as idéias de Bachelard, em L'air et les songes. No conto "O viajante clandestino", do livro Cronicando, o menino protagonista, acompanhado da mãe, aguarda na sala de espera a hora de entrar no avião. A narrativa se desenvolve no espaço do aeroporto, lugar que remete a céu, a nuvens, a vôo, a asas e a infinito. 
O texto se abre com a seguinte frase da mãe corrigindo o miúdo: "Não é arvião. Diz-se: avião" (COUTO, 1991: 24). Apresentando a criança como um ser criativo e espontâneo, ainda livre das convenções sociais e das normas cultas da gramática, a narrativa, ao mesmo tempo em que lança mão de uma estratégica e proposital simplicidade para poder expressar o lirismo próprio do universo infantil, se constitui, também, como uma metaficção, e, por intermédio da vOz narradora em primeira pessoa, vai tecendo, nas entrelinhas e nos bastidores da escritura do conto, reflexões que compactuam com a visão ingênua e poética característica da infância:

O menino estranhou a emenda de sua mãe. Não mencionava ele uma criatura do ar? A criança tem a vantagem de estrear o mundo, iniciando outro matrimônio entre as coisas e os nomes. Outros a ela se semelham, à vida sempre recém-chegando. São os homens em estado de poesia, essa infância autorizada pelo brilho da palavra. (COUTO, 1991: 24)

A princípio mero observador, o narrador, entretanto, participa internamente do narrado, pois seu discurso é permeado por um lirismo e uma sensibilidade de poeta. Seus comentários, entrecruzando sua narração, vão, através do recurso ao monólogo interior, descortinando ao leitor o que lhe vai no íntimo:

Eu assistia à criança. Procurava naquele aprendiz de criatura a ingenuidade que nos autoriza a sermos estranhos num mundo que nos estranha. Frágeis onde a mentira credencia os fortes. Seria aquele menino a fractura por onde, naquela toda frieza, espreitava a humanidade? No aeroporto eu me salvava da angústia através de um exemplar de infância. (COUTO, 1991: 25-26)

A idéia do estranhamento ao convencional caracteriza a linguagem poética desde Hegel, para quem a arte era concebida como afastamento das dimensões cotidianas. Também para os formalistas russos, o discurso artístico era entendido como desvio da norma. Segundo Jakobson, a função poética, projetando o eixo de seleção sobre a cadeia sintagmática dos discursos, produzia combinações inusitadas. Roland Barthes referiu-se à literatura como "a língua fora do poder". Maiakovski, Neruda, Gramsci, Brecht definiram a poesia como consciência e recusa das injustiças sociais. Através dos tempos, 
se fizeram inúmeros os conceitos sobre o poético, mas todos foram unânimes quanto à questão do "grau de imprevisibilidade" que caracteriza as conotações literárias.

O conto "O viajante clandestino", de Mia Couto, consegue expressar poeticamente o que significa a imaginação criadora. Associando o olhar da criança ao do poeta, afirma que ambos são seres em estado de poesia, capazes de estrear o mundo, porque conseguem se descolar do palpável e decolar pela fantasia, reinventando o mundo e a linguagem. Criam neologismos e outras maneiras originais de pensar o mundo, recuperando, desse modo, o brilho das palavras que se encontravam desgastadas pelo dizer comum.

Cúmplice do menino, o narrador-poeta o espreita, degustando-lhe as brincadeiras de querer ser passaporteiro e de fingir-se uma aeronave a voar por entre as pernas dos passageiros impacientes à espera da hora do embarque. Censura a mãe, cujo convencionalismo e rigidez reprimem o miúdo e afastam-na do universo singelo e autêntico da fantasia infantil. O estereotipado mundo adulto, regido pela aparência e pela hipocrisia social, é representado pela figura materna, cujas limitações, há muito interiorizadas, impedem-na de acompanhar o filho em seus vôos de imaginação e criatividade.

A narrativa chega ao clímax quando os passageiros se dirigem ao avião:

Chuviscava. O menino seguia seus passos quando, na lisura do alcatrão, ele viu o sapo. Encharcado, o bicho saltiritava. Sua boca maior que o corpo, traduzia o espanto das diferenças. Que fazia ali aquele representante dos primórdios, naquele lugar de futuros apressados? O menino parou, observente, cuidando os perigos do batráquio. Na imensa incompreensão do asfalto, o bicho seria esmagado por cega e certeira roda.

- Mãe, eu posso levar o sapo?

A senhora estremeceu de horror. Olhou vergonhada, pedindo desculpas aos passantes. (COUTO, 1991: 26-27)

Para Derrida, a literatura é a escritura da diferença. Para Mia Couto também, e, nesse conto, o sapo alegoriza o espanto das diferenças, pois representa o lado obscuro que a razão ocidental sempre rejeitou. Símbolo dos primórdios e da natureza, encontra-se desterritorializado, no asfalto da pista, símbolo da modernidade tecnológica do aeroporto. A estranheza que sua figura provoca 
funda uma outra lógica só perceptível à criança e ao poeta, seres cujo lirismo ultrapassa a perplexidade do inesperado encontro e se apieda daquela vida trêmula que, a qualquer momento, poderia ser esmagada. O final do conto é surpreendente:

A senhora obrigava o braço do filho, os dois se teimavam. Venceu a secular maternidade. O menino, murcho como acento circunflexo, subiu as escadas, ocupou seu lugar, apertou o cinto. Do meu assento, eu podia ver a tristeza desembrulhando líquidas missangas no seu rosto. Fiz-lhe sinal, ele me encarou de soslaio. Então, em seu rosto se acendeu a mais grata bandeira de felicidade. Porque do côncavo de minhas mãos espreitou o focinho do mais clandestino de todos os passageiros. (COUTO, 1991: 27 )

A imagem do sapo assume, assim, figuradamente, a clandestinidade própria da ludicidade poética, cuja emoção indizível só é sentida pelos que compreendem a fragilidade da vida e da existência, sendo capazes de vencer os ditames das convenções e alcançar as margens da poesia.

Também O gato e o escuro, livro de Mia Couto que, à primeira vista, parece ser apenas dedicado a crianças, segue um forte viés lírico e atinge não só infantes, mas adultos. Misturando poesia, filosofia, psicologia, psicanálise, a narrativa leva a profundas reflexões sobre a existência, os medos e os desejos humanos.

Como ocorre nas fábulas tradicionais, o protagonista é um animal, um gato chamado Pintalgato, cuja cor original, o amarelo, se metamorfoseou em preto, por causa do susto diante do escuro. Chico Buarque de Hollanda, em seu livro Chapenzinho Amarelo, também trabalha com a simbologia dessa cor, fazendo a personagem clássica dos contos infantis, Chapeuzinho Vermelho, perder a cor e ficar pálida de pavor diante do Lobo Mau. Este, como o Escuro, no livro de Mia Couto, é uma representação alegórica do desconhecido, do lado proibido, que, ao mesmo tempo, atrai e causa pânico às pessoas.

No livro de Mia Couto, letras e imagens interagem poeticamente na alma dos leitores, crianças ou não. A ilustração e o texto são muito criativos e de intensa plasticidade metafórica, operando com uma gama variada de cores que se alteram e traduzem visualmente a rica semântica da estória. Palavras e cores, enredo e figuras se enlaçam e entrelaçam em jogos de luzes e sombras, recriações lingüístico-literárias e pictóricas. 
Pintalgato é um gato que sonha ultrapassar o pôr-do-sol - portanto, os limites das formas binárias de conhecimento: dia-noite, sol-lua, bem-mal, certo-errado, etc. Uma vez, adentrando a noite, o gatinho protagonista suja suas patas de escuro e, depois, afunda nas trevas. Estas metaforizam o lado de sombra da psique humana, o inconsciente, território dos sonhos e do desconhecido. O mergulho do gatinho representa, pois, a busca de si mesmo, a procura de sua imagem refletida no Outro, ou seja, o lado do eu que se completa, desfazendo dualidades - dia/noite, claro/escuro, realidade/ficção -, que se suplementam, ensinando acerca da integralidade das coisas e dos seres no mundo.

O gato e o escuro é uma estória de gato, mas cheia de metáforas sobre os humanos. A narrativa é permeada por uma constante metamorfose de cores que efetua, ao fim, uma trespassagem do claro para o escuro, do limiar do dia para a noite. Vencendo margens e barreiras, acompanhamos Pintalgato por um percurso onírico, os pés felpudos pisando o poente, atravessando a luz para o lado dos sonhos. Assim, com ele, rompemos as fronteiras da razão, ingressando nos territórios da imaginação, descortinando o brilho do escuro.

O livro trabalha poética, filosófica e psicanaliticamente o fascínio exercido pelo proibido, pela transgressão dos limites, pelo desejo de ir além, namoriscando sempre o mundo dos sonhos. Aborda a questão da desobediência, a necessidade de correr o risco, buscando ultrapassagens e aventuras.

A imagem da imensa noitidão significa alegoricamente as outras margens do tempo e da história: espaço de criação, daqueles que, como as crianças e os poetas, não se conformam com os binarismos rotineiros e aprisionadores do senso comum, pois almejam atingir a plenitude da vida humana.

O Escuro, entre lágrimas, humanizado, chorava porque todos o temiam. Mamãe-Gata, entretanto, reconhecendo o filho sob o manto da noite, começa a ronronar-lhe ternuras: fala então do escuro de cada um, onde tudo se inventa. Mostra ao gatinho que o escuro é o inconsciente, que guarda medos e mistérios humanos. O calor das palavras da Mãe-Gata ilumina de cores o Escuro, cujo dorso se transforma num arco tenso, feito de poesia e linguagem.

Outro texto de Mia Couto que explora a questão da representação poética é o conto "Nas águas do tempo", do livro Estórias abensonhadas. São duas as personagens principais: o avô e o neto. Este acumula a dupla função de narrador e personagem, relembrando, em primeira pessoa, as aventuras no rio que desaguava no grande lago, aonde ia, com o velho avô, em sua peque- 
na canoa, provocando a aflição da mãe, que, centrada nas normas do senso comum, temia as ameaças e perigos daquele local misterioso e interdito.

Dois nítidos espaços se configuram no conto de Mia Couto: o da família, em terra firme, local da racionalidade e dos limites impostos pela sociedade, e o do rio, da pequena canoa, espaço flutuante, envolto no devagaroso dos devaneios, nas névoas do sono e dos sonhos (por essa razão, na linguagem do conto, são recorrentes as imagens que remetem ao estado de vigília entre o acordar e o dormir: o barquito cabecinhava, a canoa e a manhã ensonadas). Neblinas, cacimbações, nuvens - elementos do ar que, para Bachelard, simbolizam a imaginação criadora.

$\mathrm{O}$ avô é quem ensina a coragem e a novidade de viver. Dá lições também das tradições africanas que os nacionalismos libertadores censuraram e deixaram olvidadas: “- Sempre em favor da água, nunca esqueça! Era sua advertência. Tirar água no sentido contrário ao da corrente pode trazer desgraça. Não se pode contrariar os espíritos que fluem" (COUTO, 1994: 16).

O culto do sobrenatural faz parte, em geral, das crenças africanas e das moçambicanas, em particular. $\mathrm{O}$ avô, intuindo que os anos de colonialismo e a Independência fizeram esmaecer, na memória dos povos de Moçambique, essas práticas, leva o neto aos interditos territórios para que ele aprenda a ver os brancos panos da outra margem. Ensina ao menino que "há olhos que espiam para dentro; são os que usamos para ver os sonhos" (COUTO, 1994: 17).

O neto, entretanto, só consegue ver esses panos quando o avô faz a passagem para esse além. O menino sente o arrepioso frio do desconhecido, mas, diferentemente do filho do conto "A terceira margem do rio", de Guimarães Rosa, não foge. Acena para o avô e descobre um rio a fluir em si, compreendendo, assim, a vertigem das águas. Mais velho, retorna ao grande lago, já pai. Continuando a cadeia da tradição que, nas sociedades africanas ancestrais, era passada de geração em geração, cumpre o ritual ensinado pelo avô, levando seu filho, também, para aprender a ver os brancos panos da outra margem.

Os comportamentos do neto (no conto de Mia Couto) e do filho (no conto de Guimarães Rosa) revelam diferenças de atitude diante dos conceitos de morte, bastante diversos nas duas culturas, a africana e a brasileira. Para esta, marcada principalmente pela metafísica ocidental e pelo catolicismo, o imaginário da morte se afigura, quase sempre, como algo negativo, tenebroso, que se opõe à vida. Para aquela, devido à tradição do culto aos antepas- 
sados, morrer não significa uma ruptura com o mundo dos vivos, pois existe a crença em um constante intercâmbio de energia vital entre a vida terrena e a sobrenatural.

No texto "Nas águas do tempo", o neto vislumbra os mágicos territórios ensinados pelo avô. A ancestralidade africana, antes interditada pelos nacionalismos socialistas dos primeiros anos da Independência, irrompe, agora livre, no imaginário literário, trazendo novas formas de sexualidade que se manifestam na linguagem mitopoética do conto. A atmosfera onírica da narrativa abre espaço para o inconsciente mítico emergir e deixar os espíritos e fantasmas dos antepassados acenarem das margens da miragem. Esse processo de descentramento alarga as fronteiras do real e da censura. Os sonhos se tornam possíveis; permitem que os sentidos poéticos venham à tona, de modo a afirmarem não só as diferenças moçambicanas desfiguradas por tantas interdições e guerras, mas também a dimensão conotativa da linguagem que atinge as profundezas da poesia e do humano.

\section{Referências Bibliográficas}

BACHELARD, Gaston. L'air et les songes. Paris: Librairie José Corti, 1981. . A poética do espaço. São Paulo: Abril, 1987. . A água e os sonhos. São Paulo: Martins Fontes, 1989.

BAUDELAIRE, Charles. As flores do mal. São Paulo: Difel, 1964.

BENJAMIN, Walter. Magia e técnica, arte e política. São Paulo: Brasiliense, 1984.

BESSIÈRE, Irene. Le récit fantastique: la poétique de l'incertain. Paris: Larousse, 1974. BOSI, Alfredo. O ser e o tempo da poesia. São Paulo: Cultrix, 1983.

BOSI, Ecléa. Memória e sociedade: lembranças de velhos. São Paulo: T. A. Queiroz, 1979.

CHEVALIER, Jean \& GHEERBRANT, Alain. Dicionário de símbolos. Rio de Janeiro: José Olympio, 1988.

COUTINHO, Eduardo. "O processo de revitalização da linguagem”. In: Guimarães

Rosa. (Org. de Afrânio Coutinho). Rio de Janeiro: Civilização Brasileira, 1983.

(Coleção Fortuna Crítica 6).

COUTO, Mia. Cronicando. Lisboa: Caminho, 1991.

."Nas águas do tempo". In: Estórias abensonhadas. Lisboa: Caminho, 1994. . Contos do nascer da terra. Lisboa: Caminho, 1997. 
ELIADE, Mircea. Mitos, sonhos e mistérios. Lisboa: Edições 70, 1989. . Entrevista "O gato e o novelo". Jornal de Letras. Lisboa, 8 out. 1997. . O sagrado e o profano. Lisboa: Livros do Brasil, s. d.

GUATTARI, Félix \& ROLNIK, Suely. Cartografias do desejo. 4. ed. Petrópolis: Vozes, 1996.

KRISTEVA, Julia. Estrangeiros para nós mesmos. Rio de Janeiro: Rocco, 1994.

LYRA, Pedro. O conceito de poesia. São Paulo: Ática, 1986.

PÉLISSIER, René. História de Moçambique. Lisboa: Estampa, 1994. 2 v.

ROSA, Guimarães. "A terceira margem do rio”. In: Primeiras estórias. Rio de Janeiro: José Olympio, 1962. p. 31-37.

ROUANET, Sérgio Paulo. Édipo e o anjo. Rio de Janeiro: Tempo Brasileiro, 1981. 